\title{
NUCLEAR ENERGY FOR THE THIRD MILLENNIUM
}

\author{
Edward Teller \\ University of California \\ Lawrence Livermore National Laboratory \\ Livermore, CA 94551-0808
}

This paper was prepared for submittal to the International Conference on Environment and Nuclear Energy

Washington, D.C

27-29 October 1997

October, 1997

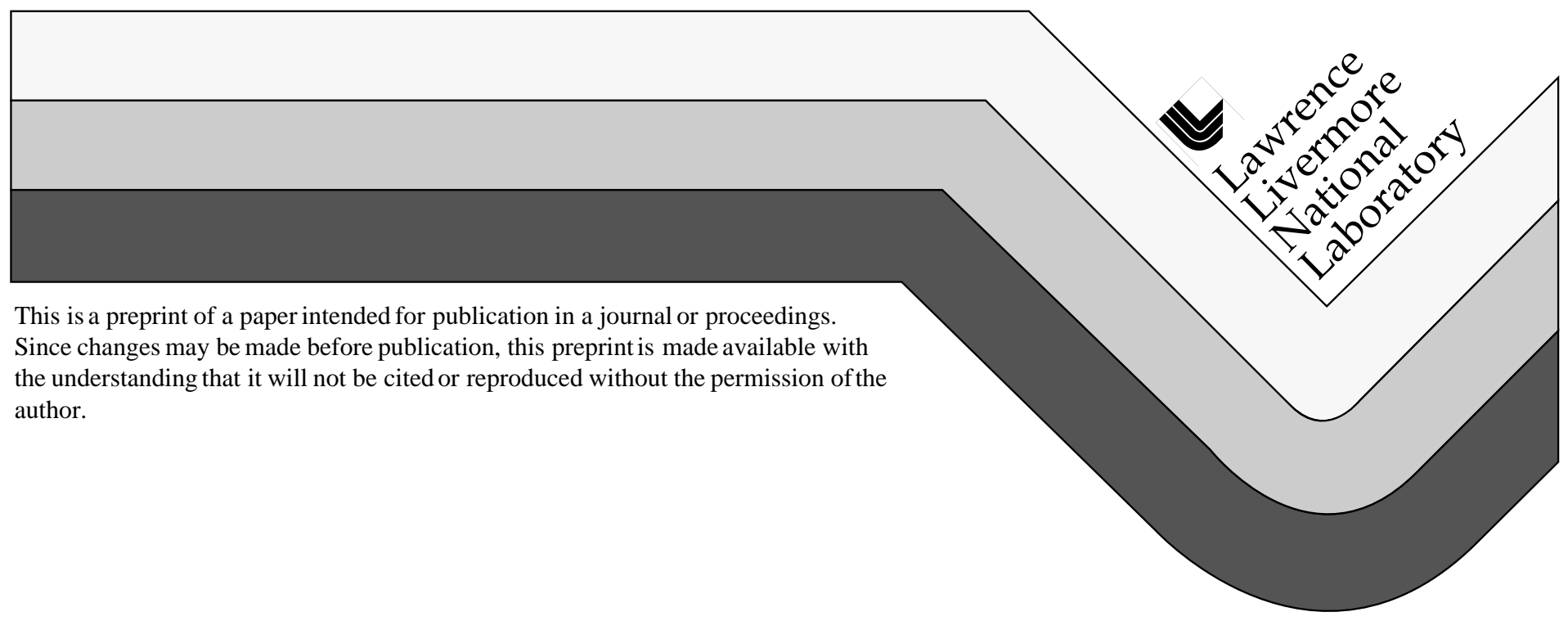




\section{DISCLAIMER}

This document was prepared as an account of work sponsored by an agency of the United States Government. Neither the United States Government nor the University of California nor any of their employees, makes any warranty, express or implied, or assumes any legal liability or responsibility for the accuracy, completeness, or usefulness of any information, apparatus, product, or process disclosed, or represents that its use would not infringe privately owned rights. Reference herein to any specific commercial product, process, or service by trade name, trademark, manufacturer, or otherwise, does not necessarily constitute or imply its endorsement, recommendation, or favoring by the United States Government or the University of California. The views and opinions of authors expressed herein do not necessarily state or reflect those of the United States Government or the University of California, and shall not be used for advertising or product endorsement purposes. 


\title{
Nuclear Energy for the Third Millennium
}

\author{
by \\ Edward Teller \\ This paper was prepared for submittal to \\ International Conference on Environment and Nuclear Energy \\ Washington, D. C. \\ 27-29 October 1997
}

October 16, 1997

\section{INTRODUCTION}

The major energy sources of today are expected to last for only a small fraction of the millennium starting three years hence. In the plans of most people, nuclear energy has been ruled out for four separate reasons:

1. The danger of radioactivity from a reactor accident or from reactor products during a long period after reactor shutdown;

2. The proposed fuels, U-235 and also Pu-239, as obtained by presently available procedures will serve only for a limited duration;

3. Energy from nuclear reactors will be more expensive than costs of present alternatives;

4. The possibility of misusing the products for military purposes is an unacceptable danger.

The development described below ${ }^{1}$ attempts to meet all four objections.

Specifically, we propose a structure as an example of future reactors that is deployed

1 This proposal has been presented in 1996 in Obninsk, Russia by Teller, Ishikawa, Wood, Hyde and Nuckolls under the title Completely Automated Nuclear Reactors in the Proceedings of the International Conference on Emerging Nuclear Energy Systems (ICENES '96), and is available at http://www-phys.llnl.gov/adv_energy_src/ICENES96.html 
two hundred meters underground in loose and dry earth. The reactor is designed to function for thirty years, delivering electrical power on demand up to a level of thousand electrical megawatts. From the time that the reactor is started to the time of its shutdown thirty years later, the functioning is to be completely automatic. This is an obviously difficult condition to fulfill. The most important factor in making it possible is to design and operate the reactor without moving mechanical parts.

At the start, the reactor functions on thermal neutrons within a structure containing uranium enriched in U-235 or having an addition of plutonium. That part of the reactor is to deliver energy for approximately one year after which a neighboring portion of the reactor containing thorium has been converted into Th-233 which rather rapidly decays into fissile U-233. This part of the assembly works on fission by fast neutrons. It will heat-up if insufficient thermal energy is withdrawn from the reactor's core, under the negative feedback action of engineered-in thermostats. Indeed, these specifically designed thermostatic units absorb neutronsif excessive reactor core heating occurs-in order to decrease heat generation and to act like automatic control rods. These units will be described below.

After the thorium in a given volume of the reactor's fuel charge is depleted, an adjacent thorium-containing portion of the fuel charge will have been convertedbred-into fissile material and is ready to continue the reaction. A schematic representation of this concept is shown in Figure 1. Actually, the thorium "reactors" in this Figure will be merged together into a single reactor system with the nuclear fuelburning reactions propagating down to the ultimate "reactor" U. (In practice, we consider placing the fuel-igniting charge in the middle of the reactor system's "fuel stick" and arrange breeding regions on both sides, shown in Figure 3.)

After all the thorium in the reactor's fuel charge has been used up, the reactor is shut down by the first positive action of the operators in thirty years. The residual radioactivity will be sealed within the reactor's core and thereafter allowed to decay in place. The initially intense radioactivity will leave the reactor products inaccessible and unusable for military purposes except if complicated, expensive and easily observed large-scale operations are performed. Having thereby avoided transportation of fission products and reprocessing significantly reduces cost and hazards. 


\section{CONVERSION OF HEAT INTO ELECTRICITY}

As stated above, production of nuclear heat in this new type of reactor system occurs at an underground depth of approximately 200 meters. In most present reactor designs, the heat is transferred to units generating electricity by the means of steam. We plan to replace water cooling by helium cooling, thereby permitting reactor core operation at higher temperature and higher thermodynamic efficiency. At the same time, helium is chemically inert at all temperatures while water becomes chemically quite active at high temperatures.

The generation of electricity is to occur above the surface or perhaps slightly underground. The generating unit and the coolant lines are indicated in Figure 1. The hot helium is to be used in a manner similar to the functioning of modern combined cycle generating units burning natural gas. The rate of power generation is regulated by the rate of pumping hot helium out of the reactor's thermostated core. This point will be discussed below.

For long-term addressing of energy supply, it is essential to burn-up a major fraction of the readily available actinides, e.g., thorium. This means that we must utilize the methods discussed under the designation of "fast breeders" (which refers to fast neutrons carrying the nuclear chain reaction). Indeed, slow (thermal) neutrons are strongly absorbed by fission products, so that any candidate slow breeder could utilize only a small fraction of thorium (or uranium) before the accumulation of the fission products would prevent further thermal neutron chaining.

The functioning of a fast breeder is practically independent of temperature and, therefore, means must be arranged to function as "control rods" in order to quench neutron multiplication at excessive temperatures. One means by which this can be accomplished is by constructing thermal-neutronic units containing the readily available light isotope of lithium, $\mathrm{Li}^{6}$, which is a strong neutron absorber. Many small reservoirs of Lithium- 6 are located outside the core of the reactor, where the residual neutrons contribute nothing to the power-producing chain reaction. Small modules of $\mathrm{Li}^{7}$ are positioned throughout the reactor's fuel charge. Thermal expansion of the liquid $\mathrm{Li}^{7}$ when the nuclear fuel reaches maximum design temperature pushes $\mathrm{Li}^{6}$ from out of the reservoirs through capillary tubes into compartments within the fuel where the neutron absorption by $\mathrm{Li}^{6}$ will quench the chain reaction. Lithium is a 
liquid throughout the temperature range of reactor operation. The modest thermal expansion of $\mathrm{Li}^{7}$ will push a $\mathrm{Li}^{6}$ reservoir's piston with considerable pressure while the other, larger face of the piston pushes $\mathrm{Li}^{6}$ at low pressure into the region of the reactor core where its neutron absorption quenches the chain reaction. (See Figure 2.) By redundantly introducing these units in large numbers throughout the nuclear fuel, we produce a very strong negative temperature coefficient of reactivity about the design temperature and insure that by varying heat withdrawal from the core, we can regulate the reactor's power output. If the coolant He moves rapidly through the reactor's core, the $\mathrm{Li}^{7}$ will contract, $\mathrm{Li}^{6}$ will be withdrawn from the core, and heat production will be stimulated. If helium moves slowly, core temperature will rise and heat production will be quenched.

Figure 3, reproduced from our 1996 paper, shows details of the propagating reaction in a 10-meter-length fuel-stick arrangement at 4 points in time over an interval of 30 years.

We expect that there may be challenges in realizing mass-producible $\mathrm{Li}$ thermostating elements for highly reliable thirty-year operation. In particular, it is important that the expansion and contraction of $\mathrm{Li}^{7}$, as well as the associated flow of $\mathrm{Li}^{6}$, should remain quickly and thoroughly reversible, even after thousands of operations. However, the needed elements could be developed and tested in high flux, slow neutron regions of an existing reactor. It is to be noted that operatorgoverned mechanical motions of control rods are replaced by a fully automatic, highly redundant arrangement that depends simply on thermal expansion.

This automatic and redundantly applied arrangement is one of several in this reactor system design which aims at reducing the probability of any accident. But we expect, that even in a case of an accident, human health will not be endangered.

It is necessary to point out that even with inclusion of Chernobyl into the overall statistics, lives lost divided by energy generated throughout the world has been far less for nuclear reactors than for all conventional methods of electricity generation.

Sohei Kondo, in a specific study entitled Health Effects of Low-level Radiation, states in the Preface on Page xiv: 
The collected data strongly suggest that low-level radiation is not harmful, and is, in fact, frequently 'apparently beneficial' for human health. The data are incomplete, however, and presentation of these facts alone will not suffice to allay the fear of low-level radiation, especially with regard to the risks for congenital anomalies and cancer.

Transportation of reactor products to a central location and storage of the products in a limited region may increase hazards. Our present proposal is to avoid the costs of such transportation and storage and at the same time decrease hazards by locating power reactors in appropriate regions. The main requirement is absence of water that might transport radioactivity to the surface and thus into the biosphere. If in course of geologic changes, water should approach the ancient reactor site, we calculate that due to the high temperature in this region arising from the slow decay of the reactor's still-contained nuclear waste products, the water will evaporate before it reaches the vicinity of the reactor itself. In planning the locations of these reactors, it will be necessary to give special attention the dry regions of the Earth's surface. At the same time, it also appears to be desirable to locate reactors in relatively loose earth in which earthquakes are not apt to open fissures.

\section{ANSWERS TO THE FOUR OBJECTIONS AGAINST NUCLEAR POWER}

1. Numerous nuclear explosions have been performed at depths of roughly 200 meters in Nevada in comparatively loose earth. The energy made swiftly available is often comparable to or more than what could be released in a reactor accident. In spite of this, no dangerous amounts of radioactivity have reached the surface. In addition, useful information was obtained about the slow migration of radioactivity underground. We believe that these results may be applied anywhere else, in comparable conditions.

It follows that the reactor should be so located as to exclude access by water for the present time and as far into the future as possible. While no guarantee can be

given concerning the effects of geological changes, the engineered heating of the material surrounding the reactor happens to be a favorable factor. One may thereby expect that invasion by water (unless it is rapid and massive) will be counteracted by 
its evaporation before it reaches the vicinity of the now-ancient reactor and its residual radioactivity.

2. In our proposal, enriched uranium and plutonium are used for only a few percent of the nuclear heat eventually generated. The great preponderance of the energy developed comes from thorium and this element is available in practically mineable deposits in quantities sufficient for millennia of present-day electricity generation.

3. Expense of future deployment and operation is hard to predict. The needed excavation is an old and well-developed technology and is not likely to contribute more than 10 to 20 percent of the total system cost.

Long-term availability of the fuel has been already mentioned and such fuel can be used without any expensive intermediate step such as isotope separation.

One of the particularly important innovations that have been proposed is the fully automatic operation, effectively obsoleting human intervention. Because of its unusual character if applied to an operation over many decades, this is a particularly critical issue. One reason why I hope for success is the relatively simple functioning of the energy-producing mechanism which we expect to work without programmed moveable parts. It is this automatic operation that may need most attention in fully developing the proposed reactor technology.

A considerable part of the cost in the U.S. of nuclear power at the present time is due to unnecessary delays in creating new nuclear power plants, delays not seen elsewhere. These delays result in money "lost" paying interest on early investment. Standardized design and decrease of fear of accidents should greatly facilitate elimination of such delays and costs.

Even at the present time in the U.S., nuclear power generation is accomplished without a major fraction of the electricity cost being due to costs of operation. In the proposed scheme, the cost of operating the reactor should be much smaller.

A closely-related question is the availability of reliable operators. In worldwide usage including developing countries, fully-qualified operators may be 
unavailable in quantities required. If, indeed, we can do without them, this would be a great advantage in making this energy source generally and safely available.

4. The connection between energy production and material for nuclear explosives is obviously worrisome. In our proposal, the residual fissile material is left underground in circumstances that will remain radioactive for centuries. To obtain this material will require automated equipment in massive, sustained operations. The use of such equipment will be complicated and expensive. If arrangements are made to overcome these difficulties, it will require the kind of complicated and large-scale operation that is difficult to keep secret. Thus, the widespread availability of nuclear electricity will be achieved without substantial danger of proliferation of nuclear explosives.

\section{CONCLUSION}

The acceptance of our proposal is hampered by the circumstance that rather unprecedented procedures are needed. Modern technology has in general been exercised by ample use of humans in all phases of planning, construction and operation. We are proposing the practical elimination of people from the operational phase. To do this in a reliable manner will obviously engender opposition.

It should be emphasized that three of the four objections against nuclear power are resolved in part by reducing the number of people involved and, if possible, by eliminating them from the operational phase.

The serious accidents of Three Mile Island and Chernobyl were brought about by severe operating mistakes. Simple adherence to existing safety procedures would have avoided both accidents. As long as the public insists on complete avoidance of accidents, we must insist on straightforward safety measures operating in an automatic manner. As has been pointed out, eliminating the unreliability which may be inherent in human operators may be a necessary step if nuclear energy production should have worldwide application.

Most importantly, the automatic operation would make it possible to operate nuclear power reactors under governments which may not be entirely trustworthy. 
The peculiar conclusion is that underground reactors are not compatible with imperfect solutions of a number of our problems. But they can have really great advantages if all the problems indicated are considered. The proposed solutions of underground location and breeding are not novel. But the combined effects of these innovations may deserve more attention.

I want to thank Dr. Lowell Wood for his help and for important contributions. This work was performed under the auspices of the U.S. Department of Energy by Lawrence Livermore National Laboratory under contract No. W-7405-Eng-48. 


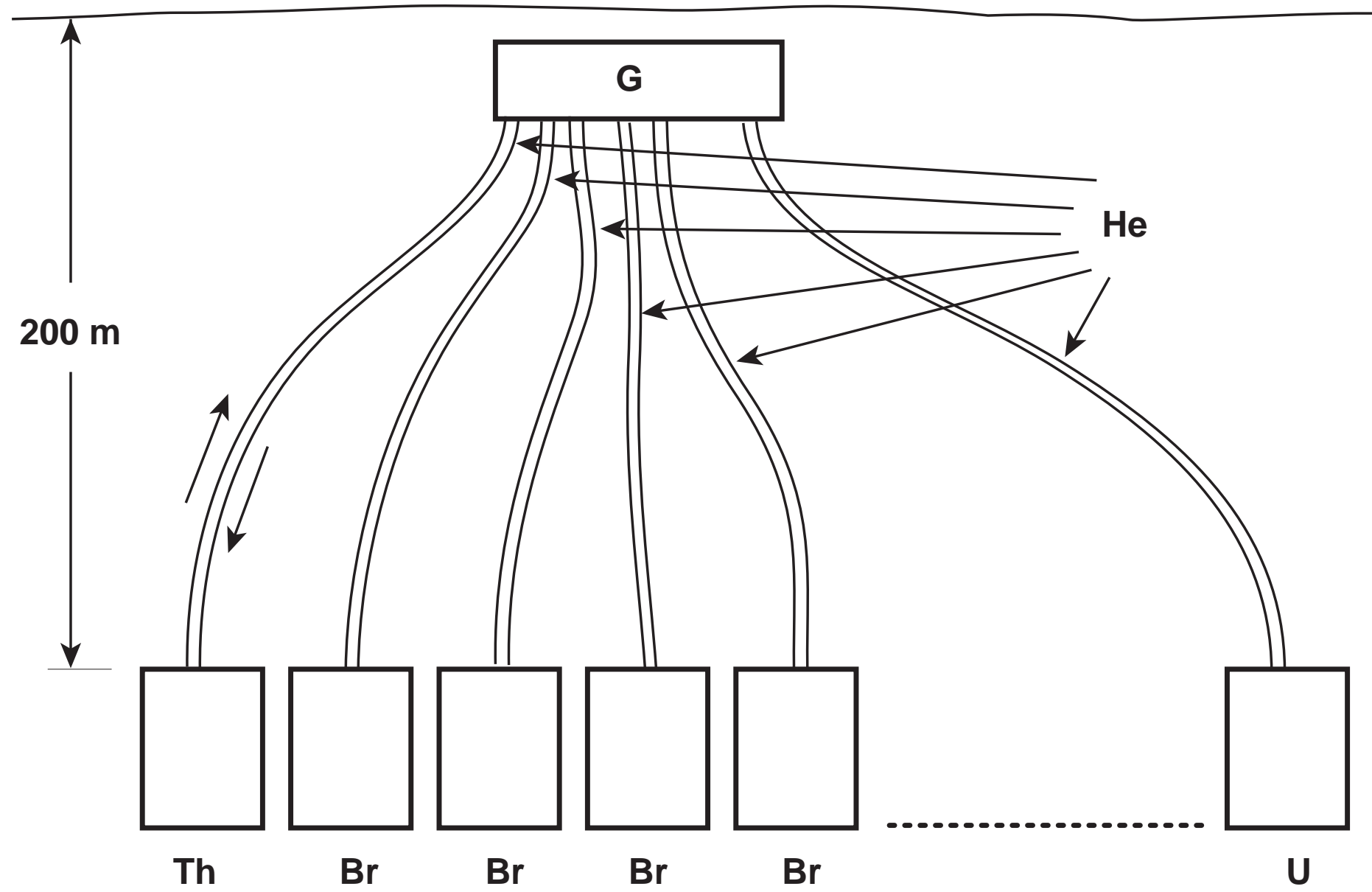

Outline of reactors $\mathbf{2 0 0}$ meters underground. $\mathrm{G}$ is the generating unit: Helium $(\mathrm{He})$ coolant connectors transport heat from reactor to generator. There are a series of breeder reactors to the ultimate $(U)$ reactor. 


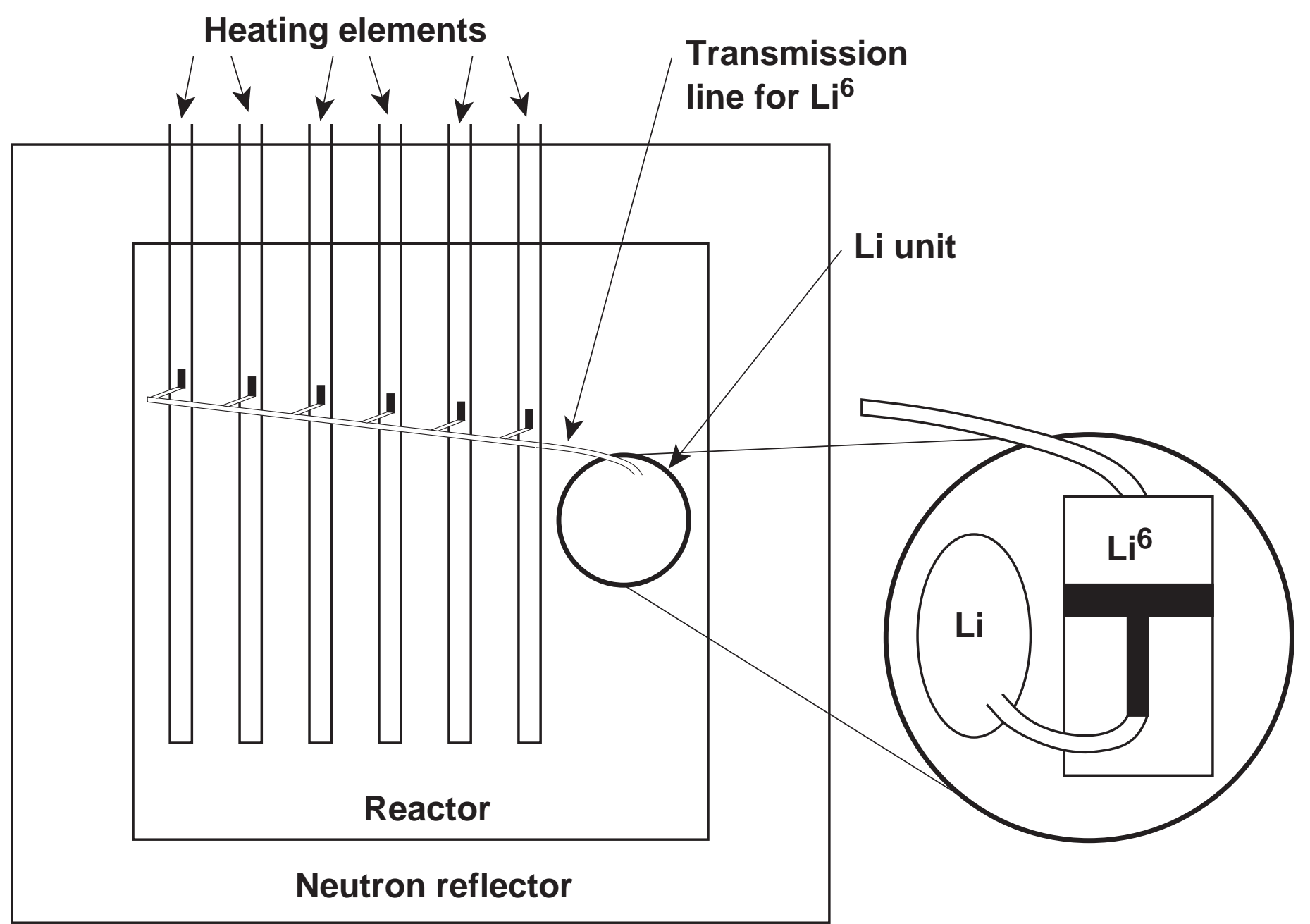

In the enlarged Li drawing on the right, the space below the poston is empty except for the pipe at the bottom of the piston T. The figure indicates how the small lower end of the piston $\mathrm{T} \mid$ acts upon the large upper surface. Containers at the end of the $\mathrm{Li}^{6}$ lines regulate the operation by being empty or full.

Figure 2 


\section{Propagation of burning in the breeder reactors}
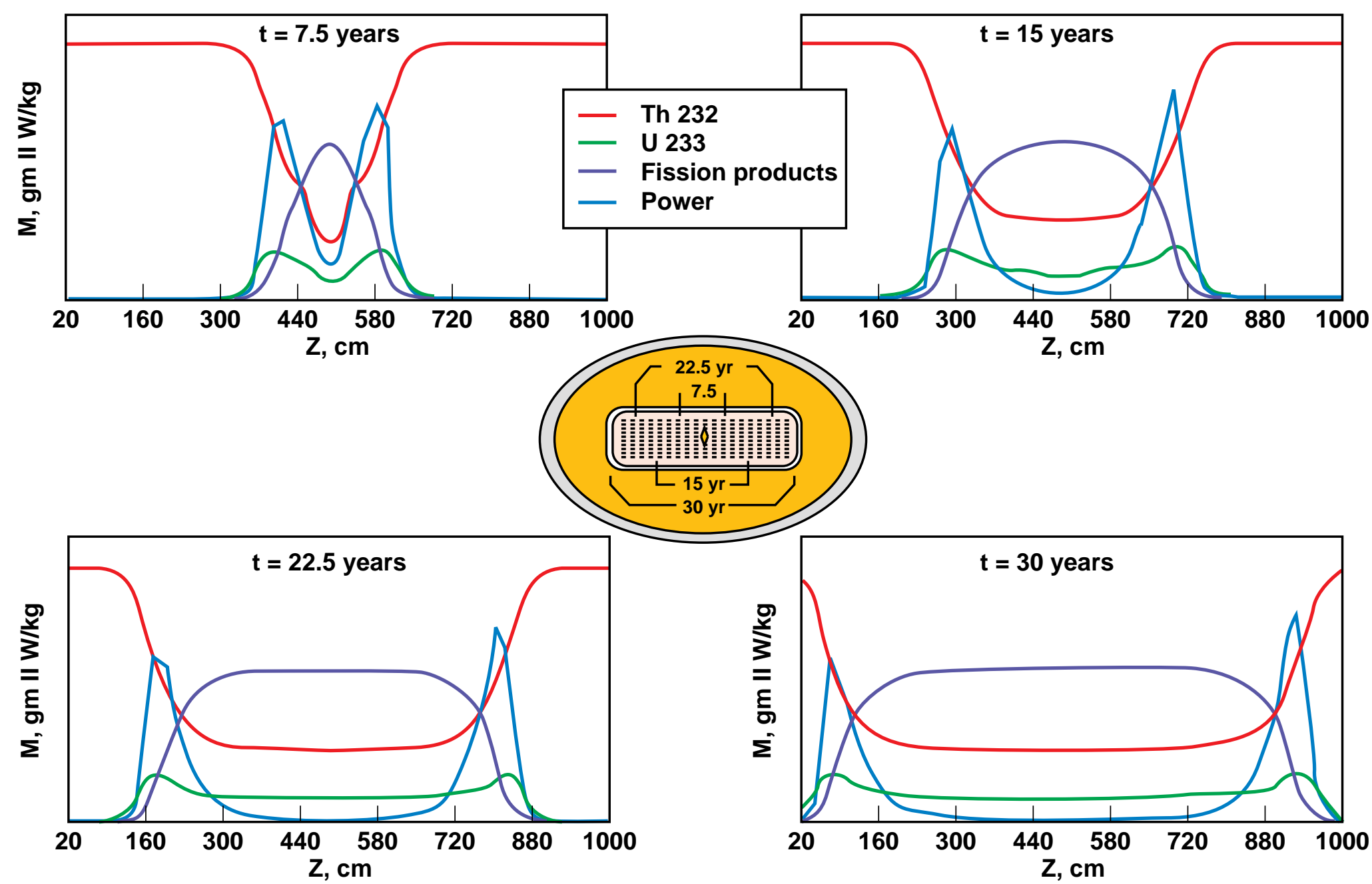

Shown in the middle is an outline of the reactors. The original thermal reactor in the middle and breeders continuing on both sides. (Figure 1 shows them on one side) with ultimate reactors on both ends. This miniature drawing indicates how far the reaction has proceeded in $7.5,15,22.5$, and 30 years. The 4 figures on the sides show the unburned amount of plutonium 232, uranium 233, the fission products, and the rate of heat of these at the 4 times indicated. The contribution of the center reactor, is neglected at the advanced times to which this figure refers. The figures indicate only the relative and not the absolute values. 


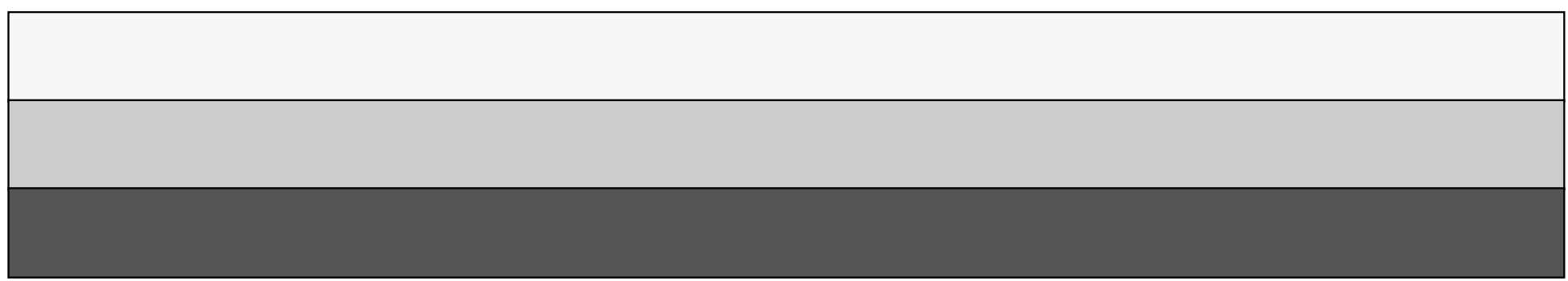

